Original Research Paper

\title{
Effect of Exhaust Gas Temperature on the Performance of Automobile Adsorption Air-Conditioner
}

\author{
${ }^{1}$ Abdul Hadi N. Khalifa, ${ }^{1}$ Ali H. Jabbar and ${ }^{2}$ Jamal A. Muhsin

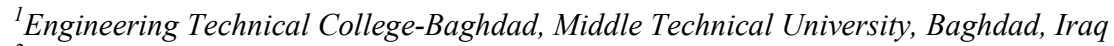 \\ ${ }^{2}$ Ministry of Higher Education, Baghdad, Iraq
}

Article history

Received: 24-05-2015

Revised: 03-06-2015

Accepted: 27-06-2015

Corresponding Author: Abdul Hadi N. Khalifa

Engineering Technical College-

Baghdad, Middle Technical

University, Baghdad, Iraq

Email: ahaddi58@yahoo.com

\begin{abstract}
An adsorption air conditioning unit of two beds was designed and built. Each bed was constructed from two concentric copper pipes sets, the length of the pipes in each set was $1500 \mathrm{~mm}$ pipe. The inner pipe was $50 \mathrm{~mm}$ in diameter while the outer pipe was of $100 \mathrm{~mm}$ diameter. The inside surface of the outer pipe and the outside surface of the inner pipe were covered by two active carbon layers which were separated from each other by a $5 \mathrm{~mm}$ space, to allow for methanol vapour penetration through the two layers. Each bed was inserted in a metal pipe to convey the hot stream of exhaust gases, to form a two passes heat exchanger. To complete the adsorption air conditioner cycle, an evaporator and condenser were connected to the two beds. Exhaust gases were produced by a propane burner, which can be adjusted to deliver hot gases at a temperature range of 80 to $140^{\circ} \mathrm{C}$. The work showed that there was direct relationship between the hot gas temperatures that was used to heat the bed and the chilled water temperature. When the hot gases temperature exceeded $120^{\circ} \mathrm{C}$, the whole cycle time increased along with a slight increase in chilled water temperature with a reduction in COP. A minimum chilled water temperature of $7.6^{\circ} \mathrm{C}$ was obtained. This chilled water was supplied to a fan coil unit to maintain an inside temperature of $24.2^{\circ} \mathrm{C}$ for a $600 \mathrm{Watt}$ conditioned space load. The maximum cycle COP was about 0.31 when the hot gas temperature was $120^{\circ} \mathrm{C}$.
\end{abstract}

Keywords: Adsorption, Refrigeration, Automobile, Air-conditioning

\section{Introduction}

Typical refrigeration system used on large refrigerated trailers and for $\mathrm{A} / \mathrm{C}$ on large buses is a diesel powered vapor compression refrigeration system. The Diesel driven compressor data, has been obtained from two leading transit refrigeration system companies, which are, Carrier and Thermo King Corporations. Reviewing a large amount of data from those manufacturer, showed that vapour compression systems compressors, typically require ( 25 to $30 \mathrm{HP}$ ) input power data on the amount of diesel fuel consumed per hp-hr indicates that smaller bore diesel engine consumes 0.173 $\mathrm{kg} / \mathrm{hp}$.hr, while large one consumes $0.145 \mathrm{~kg} / \mathrm{hp} . \mathrm{hr}$ (Obert, 1973). A leading manufacturer of refrigerator trailer, report that, an average refrigerator trailer operates between 1500 to $1700 \mathrm{hr} /$ year, in which the refrigerator is $50 \%$ in duty cycle. This means that the compressor of refrigerator trailer consumes from 3000 to $4000 \mathrm{~kg}$ of diesel fuel per year. A typical diesel engine exhaust gas analysis, shows that each kilogram of diesel fuel produces about $20.2 \mathrm{~m}^{3}$ of exhaust gas, in which the volumetric analysis of $\mathrm{CO}$ is about $2.7 \%$. Therefore, the volume of exhaust gas emission from refrigerator compressor operation can be as much as $114.7 \mathrm{~m}^{3} / \mathrm{hr}$, i.e., the volume of $\mathrm{CO}$ can be about $3.0969 \mathrm{~m}^{3} / \mathrm{hr}$. In a standard atmospheric condition of $15.5^{\circ} \mathrm{C}$ and $1 \mathrm{bar}$, the emission of $\mathrm{CO}$ is about $2890 \mathrm{~kg} /$ year which means an additional increase in Global Warming Potential (GWP) and more acid rain (Karnaukhov, 2001). Recently, a commercial ice maker has been developed for diesel fishing vessels (Wang et al., 2006). However, this scarcely used technology could be extended to many other configurations, since the adsorption compressor is thermally driven, by any of the acceptable energy sources such as (fossil fuels, biofuels, waste heat and solar energy). Zhang and Wang (1997), presented a numerical study of the dynamic performance of an 
adsorption cooling system for automobile waste heat recovery. A lumped parameter non-equilibrium model was developed and used to investigate and optimize the waste heat cooling system. The effects of the operating temperatures and the overall heat transfer coefficient on the system performance were investigated. It was found that the SCP is more sensitive to parameter changes than the COP and improving the UA is the most effective way to obtain an increased SCP, but only in the ranges below the threshold value, which is determined by the overall mass transfer coefficient. Zhang (2002), studied an adsorption air conditioning system with the adsorption beds were regenerated by a bus exhaust gases. The assessed COP was 0.38 and the SCP was $25.7 \mathrm{~W} / \mathrm{kg}$. The coefficient of waste heat cooling (WCOP) was found to be of 0.31. Jiangzhou et al. (2002), has designed a refrigerator for a locomotive driver's cabin. The cooling power of such a system under typical running conditions ranged from 3 to $5 \mathrm{~kW}$, with a COP of 0.21 . The temperature inside the cabin was between 4 to $6^{\circ} \mathrm{C}$ lower than the ambient temperature, while the same cabin usually had a temperature of 2 to $5^{\circ} \mathrm{C}$ higher than the ambient temperature without refrigeration. Zhong et al. (2010), Propose a model of an adsorption air conditioning system using the zeolite-water working pair, the system performance with different operating cycle was reported. The results show that the COP of the system increases with the length of the cycle period but the total cooling capacity decreases during the same period of operation. Khalifa et al. (2011), built a two beds active carbon-methanol adsorption chiller of 1.5 tons capacity. The switching between desorption and adsorption phases was activated by a simple electric system. The adsorption chiller was driven by hot water with a temperature range of 70 to $100^{\circ} \mathrm{C}$. It was found that using the mass recovery process increased the initial methanol concentration in the generator during operation resulting in an improved cycle $\mathrm{COP}$ and SCP. At an outdoor temperature of $25^{\circ} \mathrm{C}$, the $\mathrm{COP}$ of this adsorption chiller was about 0.301 while the SCP was about $0.35 \mathrm{~kW} / \mathrm{kg}_{\mathrm{AC}}$. Eventually, a mass of $200 \mathrm{~kg}$ of water could be chilled from 10 to about $7^{\circ} \mathrm{C}$ in about 14 min. Tiwari and Parishwad (2012), presented an adsorption refrigeration system powered by exhaust heat. The cooling capacity for a truck cabin was estimated at 1 ton, a scale of 3.5:1 was decided and a prototype of $1 \mathrm{~kW}$ has been designed and developed and tested in laboratory. A cooling effect of 1 to 1.2 $\mathrm{kW}$ has been obtained. The COP of the system was in the range of 0.4 to 0.45 . The heating time required to achieve the cooling effect is around 10 minutes. Sharafian and Majid (2014), Presented an assessment of available adsorber bed design of waste-heat driven adsorption Air Conditioning System (ACS), they classified the previous studies based on the ACS working pairs, cooling capacity, cycle time, COP and adsorber bed to adsorbent mass ratio. Based on these data, the effects of different adsorber bed designs were investigated on the adsorber bed to adsorbent mass ratio and COP to identify the best adsorber bed designs suitable for vehicle air-conditioning and refrigeration applications. This work focused on the attempt to quantify potential reductions of emissions from the bus $\mathrm{A} / \mathrm{C}$ and refrigerated trailer engines, by utilize the waste heat from engine exhaust gas. This can be reduced the compressor load on the engine and reduce fuel consumption. The waste heat would be used as input power for an adsorption compression refrigeration system.

\section{Experimental Work}

\section{Apparatus Construction}

The adsorption Air conditioner unit consisted of two beds; each bed was built from three main concentric pipes. The inner pipe was a circumferentially finned copper pipe, of $166 \mathrm{~cm}$ long and $5 \mathrm{~cm}$ inner diameter. There were 21 circumferential fins distributed uniformly along the pipe. Each fin was made of $7 \mathrm{~cm}$ outer diameter steel disc with 8 radial holes of $5 \mathrm{~mm}$ diameter each. These holes allowed methanol vapour to pass through the bed easily. The first active carbon layer was made of $3.5 \mathrm{~kg}$ of a $2 \mathrm{~mm}$ diameter and $3 \mathrm{~mm}$ height of tubular grain activated carbon, which covered the inner finned pipe. A double layer tubular metal screen (40 holes $/ \mathrm{cm}^{2}$ gauge) separated by $5 \mathrm{~mm}$ space was used to hold the activated carbon around the inner pipe. The second active carbon layer was constructed by filling the space between the inner and outer copper pipe. The bed was inserted in a metal tube to complete the adsorption bed, as shown in Fig. 1.

A double row, air cooled condenser, with (6) tubes per row was used as the unit's condenser. The upper and lower ends of tubes were collected by headers and risers of $18 \mathrm{~mm}$ in diameter. The cooling coil was formed by a collection of 15 vertically installed, $19 \mathrm{~mm}$ diameter copper tubes. The coil was inserted in a stainless steel container of $26 \mathrm{~mm}$ diameter and $28 \mathrm{~mm}$ height (length), the assembly of the cooling coil and the container constitutes the water chiller.

A combustion chamber was built with $150 \mathrm{~mm}$ diameter and $100 \mathrm{~cm}$ length steel pipe equipped with a propane burner. This combustion chamber was used to simulate the exhaust gas produced by a typical automotive engine. The chilled water produced by the adsorption air conditioner was used to cool the cooling coil of a fan coil unit. The fan coil unit had service space of $170 \times 80$ and $73 \mathrm{~cm}$ height. The load in the space was about 600 Watt. Figure 2 shows the final shape of the adsorption air conditioner. 


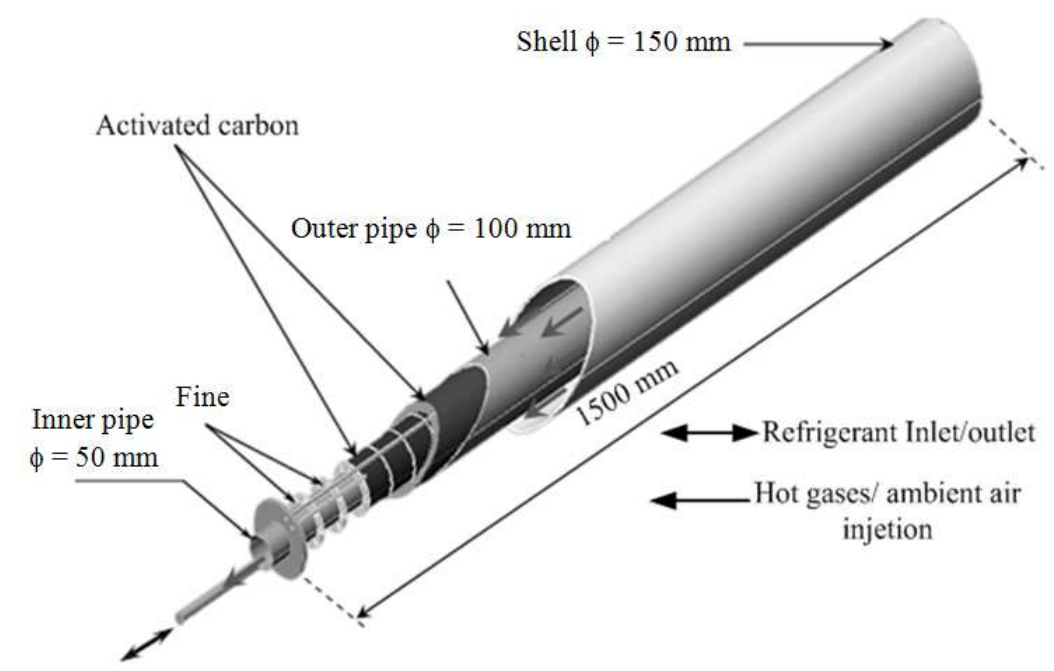

Fig. 1. Details of adsorption bed

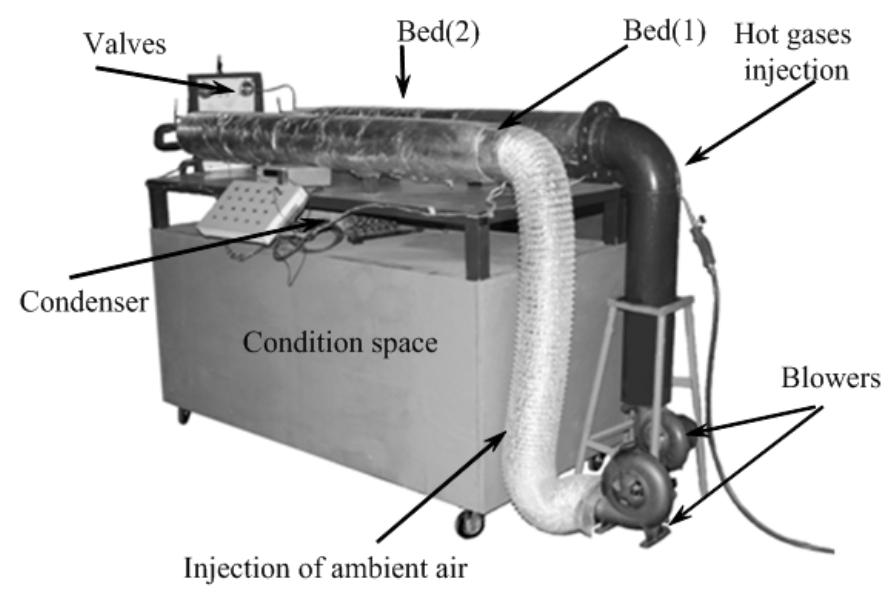

Fig. 2. Desorption air conditioner

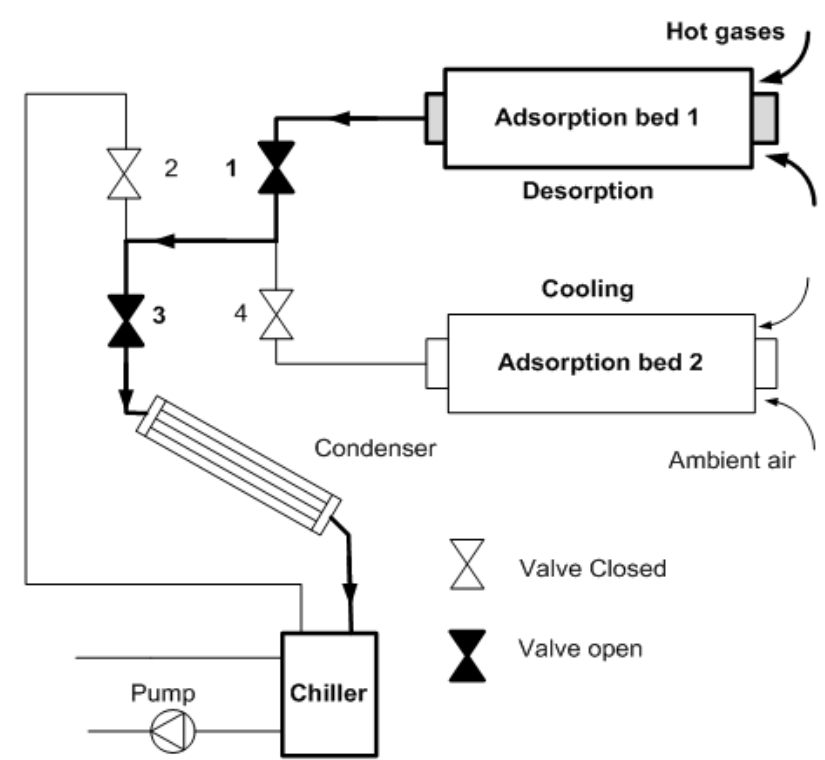

(a)

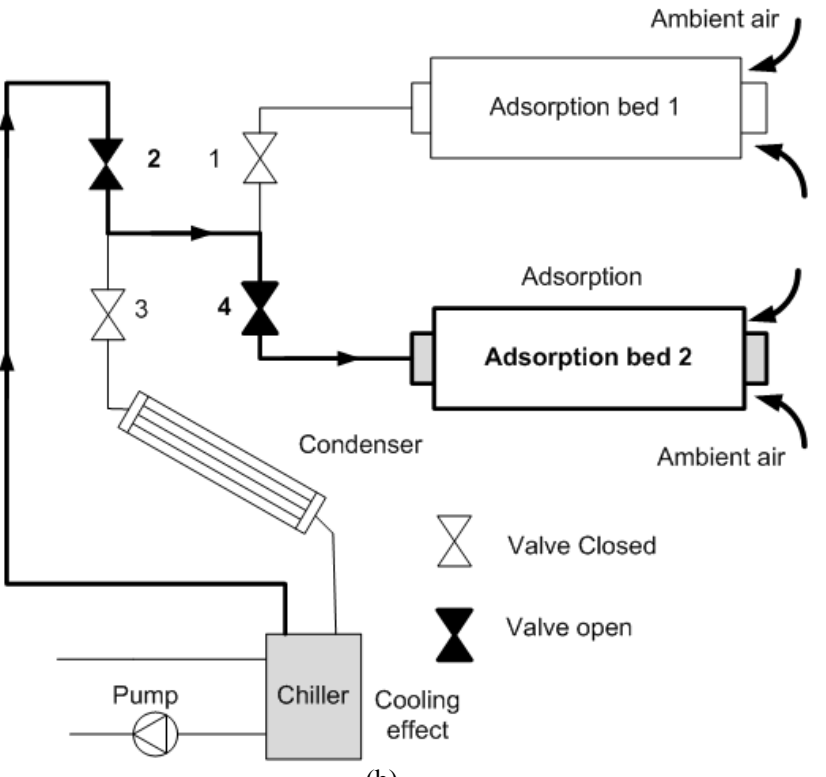

(b) 


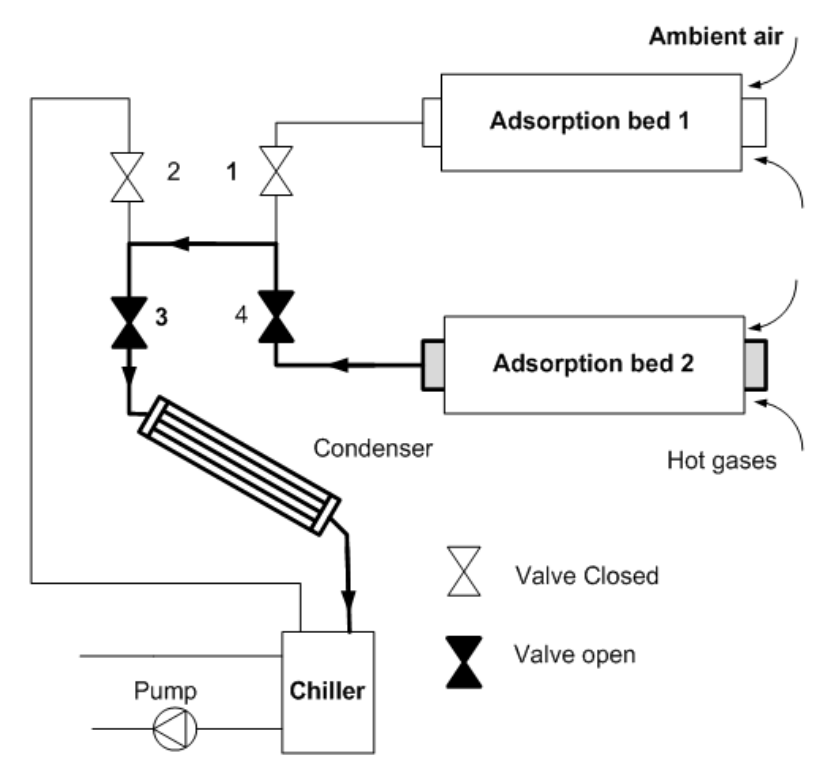

(c)

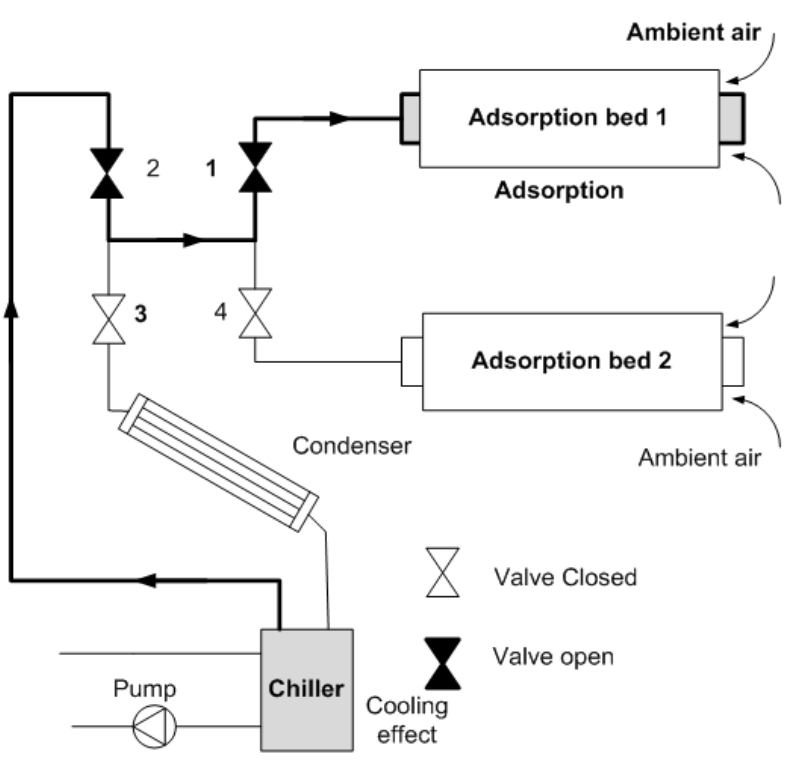

(d)

Fig. 3. (a) Heating, pressurization and desorption of bed (1), Cooling and depressurization of bed (2) (b) Adsorption and Evaporation process by cooling bed (2), Cooling and depressurization to bed (1) (c) Heating and desorption of bed (2) (d) Cooling and adsorption of bed (1)

\section{Apparatus Trial Operation}

A test running of the adsorption air conditioner was conducted prior to the actual experiment sets. Referring to Fig. 3a, at first stage all the methanol was collected in bed (1), all valves (namely 1,2 3 and 4) were closed. The initial pressure of the system was $5 \mathrm{kPa}$. As the hot exhaust gases passed through the heating path of bed (1), the methanol pressure increased rapidly from $5 \mathrm{kPa}$ to about $33 \mathrm{kPa}$ (depending on exhaust gas temperature). During this period of time, bed (2) was cooled by ambient air stream. The pressure of bed (1) increased until the entire methanol was desorbed from the bed after which the bed pressure remained constant. The condenser was connected to bed (1) by opening valves 1 and 3 leading to a fall in bed (1) pressure to about 26 $\mathrm{kPa}$, as shown in Fig. 3b. The condensation of methanol vapour lead to another fall in the pressure to about 20 $\mathrm{kPa}$. Liquid methanol produced by condensation process was collected in the cooling coil of the chiller. At the second stage (cooling and adsorption processes), the cooling coil was isolated from bed (1) by closing valves 1 and 3 and connected to bed (2) by opening valves 2 and 4 . Bed (1) was then cooled by ambient air stream and bed (2) was heated by hot gases stream. As liquid methanol started to evaporate in the cooling coil, the adsorption process began in bed (2) leading to a fall in bed pressure to about $13 \mathrm{kPa}$ followed by another fall to $5 \mathrm{kPa}$ after $5 \mathrm{~min}$. After adequate period of time, the entire liquid methanol in the coil evaporated. This was the first half of the cycle, which was accomplished by completing the adsorption of methanol vapour in bed (2).
The second half of the cycle started by isolating bed (2) from the cooling coil and connecting it to the condenser through closing valve 2 and opening valve 3 , as shown in Fig. 3c. The desorption and condensation process of the accumulated liquid methanol in the cooling coil took place. The final evaporation and desorption process started by connecting the cooling coil to bed (1) through closing valves 3 and 4 and opening valves 1 and 2, as shown in Fig. 3d. The four stages cycle was completed when the methanol returns back to bed (1). The effect of hot gas stream temperatures on each process time, whole cycle time, SCP and cycle COP was studied. The adsorption air conditioner was tested under different hot gas stream temperatures ranged from 80 to $140^{\circ} \mathrm{C}$, in steps of $10^{\circ} \mathrm{C}$.

\section{Results and Discussion}

The operating time is the time required to perform one complete cycle, starting from the heating and pressurization process and ending with cooling and adsorption process, while the whole cycle time is the time required for the complete chilling of water, thus constitutes of more than one cycle.

Figure 4 shows the operating cycle time when the heating gas temperature is $80^{\circ} \mathrm{C}$. It can be seen from the figure that it requires about $18 \mathrm{~min}$ to raise the pressure of bed (1) from 5 to about $33 \mathrm{kPa}$ (heating and pressurization process). As a result of opening the valve connecting bed (1) to the condenser, bed pressure falls from 33 to about $20 \mathrm{kPa}$. The methanol vapour condenses at about $20 \mathrm{kPa}$ with a corresponding saturation temperature of $56.6^{\circ} \mathrm{C}$. 
The condensation process needs about 38 minutes to complete. As a result of opening the valve connecting the evaporator to bed (2), the pressure falls from 20 to $5 \mathrm{kPa}$ in about $5 \mathrm{~min}$. During evaporation process, the evaporator pressure remains constant at $5 \mathrm{kPa}$. When the cooling process commences, the temperature of cooling coil falls to about $8.6^{\circ} \mathrm{C}$ for about $12 \mathrm{~min}$. Methanol vapour produced by evaporation process is absorbed by bed (2), so the methanol is transferred from bed (1) to bed (2) during the cycle mentioned above. This cycle is repeated to make another cooling effect in the evaporator. The whole cycle time is about $9.26 \mathrm{~h}$, during this time, the temperature of $12 \mathrm{~kg}$ of water falls from 35 to $11.3^{\circ} \mathrm{C}$. While the space temperature with $600 \mathrm{~W}$ load (the heat loss to the environment is not included) falls from 32 to $28^{\circ} \mathrm{C}$ after the fan coil started.

Figure 5 shows the variation in process time, chilled water temperature, whole cycle time and SCP, cycle $\mathrm{COP}$ with hot gas temperature changes. It can be seen from the figure that as the hot gas temperature increases, the chilled water temperature decreases. Minimum chilled water temperature is achieved when the hot gas temperature is $120^{\circ} \mathrm{C}$. As the hot gas temperature increases more than $120^{\circ} \mathrm{C}$, the chilled water temperature remains constant while the cycle COP decreases. Also, there is an increase in a whole cycle time of about 12 $\mathrm{min}$ as the hot gases temperature increases from 120 to $14^{\circ} \mathrm{C}$. Thus, it can be concluded that the optimum hot gases temperature is $120^{\circ} \mathrm{C}$.

Figure 6 shows the variation of chilled water, space and supplied air temperature with the time when the hot gas temperature is $120^{\circ} \mathrm{C}$. It can be seen from the figure that the water temperature falls from 35 to $21^{\circ} \mathrm{C}$ in about $15 \mathrm{~min}$. The water temperature remains constant at $21^{\circ} \mathrm{C}$ for about one hour. The fan coil is turned $\mathrm{ON}$ when the chilled water temperature reaches $7^{\circ} \mathrm{C}$. A fluctuation in water temperature ranging from 22 to $12^{\circ} \mathrm{C}$, separated by constant temperature period is observed. It can be seen from the figure that an initial space temperature of $32^{\circ} \mathrm{C}$ falls to about $21^{\circ} \mathrm{C}$ after the fan coil was turned $\mathrm{ON}$.

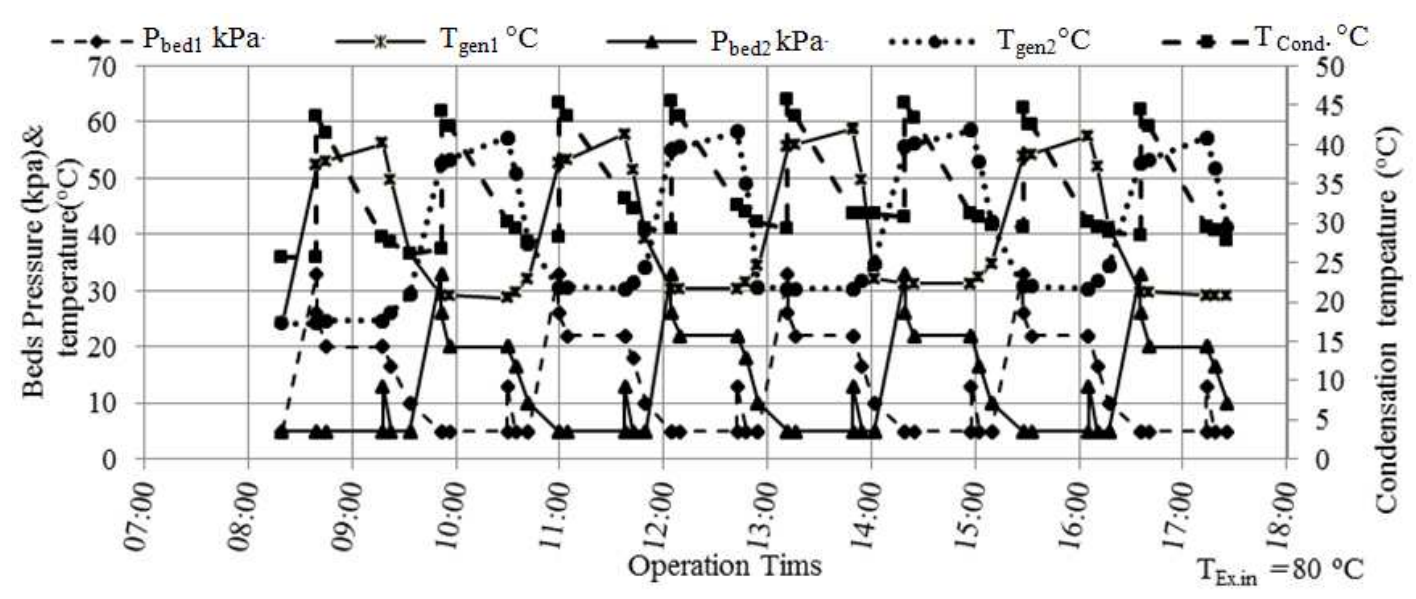

Fig. 4. Performance of the adsorption air condition unit with the time, when the hot gas temperature is $80^{\circ} \mathrm{C}$

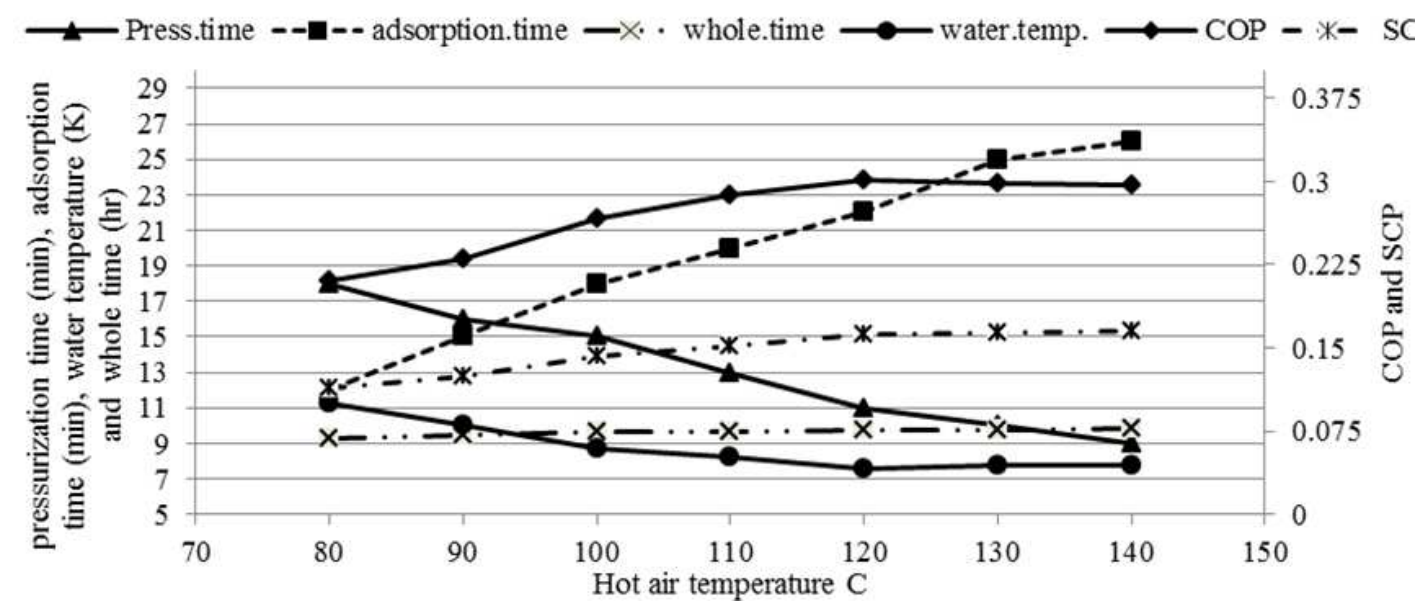

Fig. 5. variation of cycle time, temperature, with hot gases temperature 


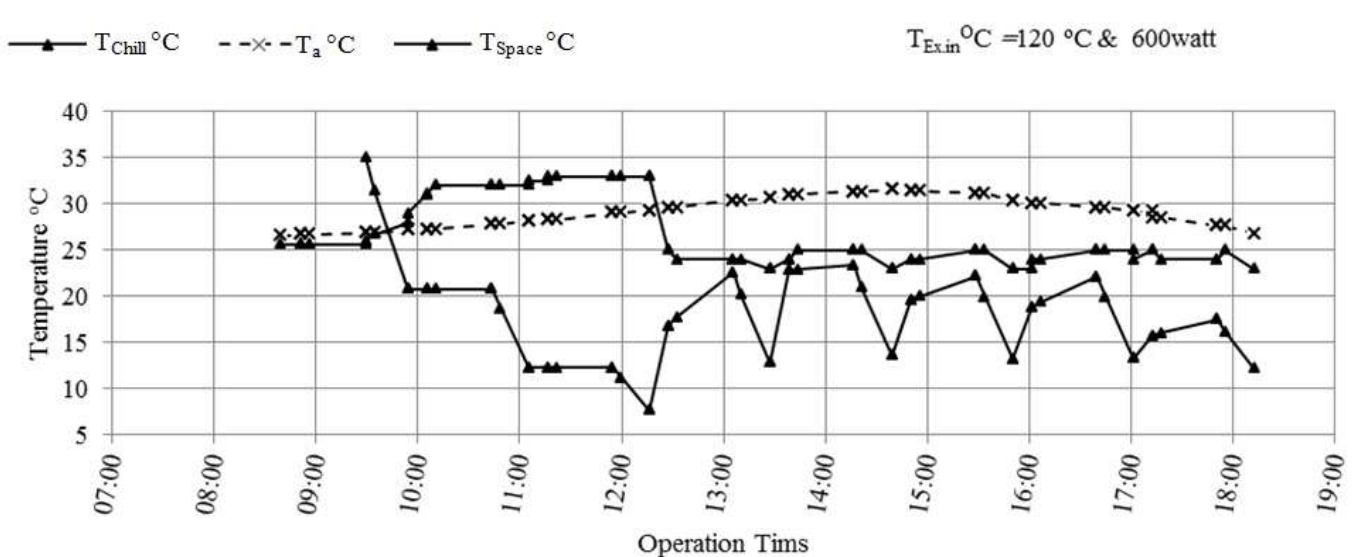

Fig. 6. Behavior air, chilled water and ambient air in space condition unit with the time 1-2- Heating and pressurization process. 2-3- Opning valve moment. 3-4- relesing and condensation process.
4-5- cooling and depressurization process.

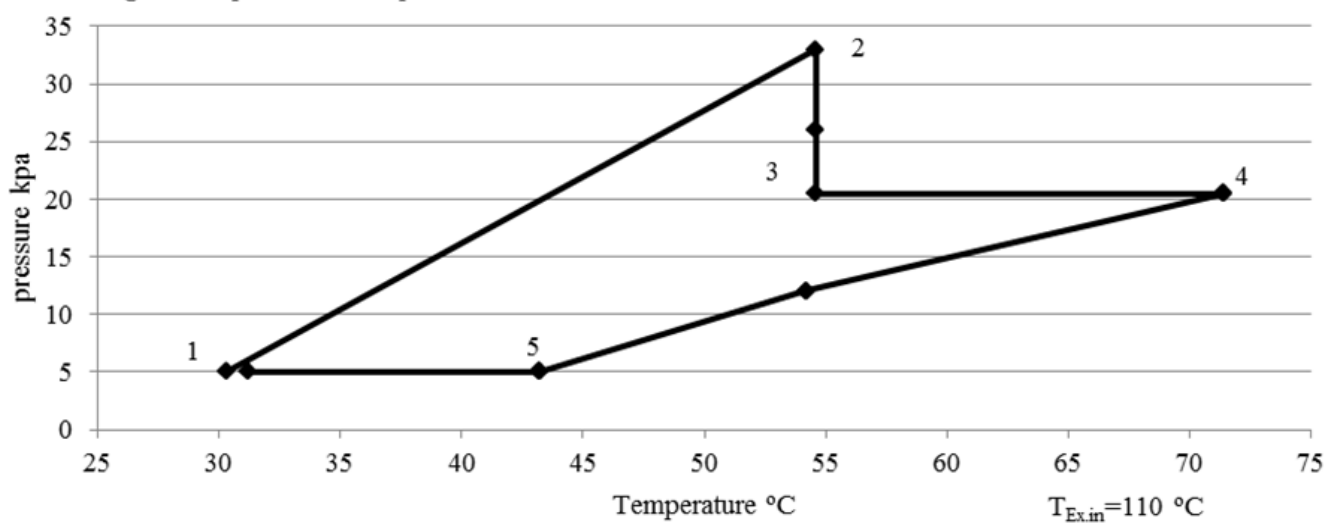

Fig. 7. Adsorption desorption cycle of adsorption air-conditioner

Figure 7 shows the adsorption-desorption cycle of the adsorption air conditioner for a hot gas temperature of $110^{\circ} \mathrm{C}$. Bed (1) is at the initial condition of $5 \mathrm{kPa}$ working pressure. When the hot gases pass through bed body, both temperature and pressure increase. The pressurization process 1-2 completes when the bed pressure reaches about $33 \mathrm{kPa}$ (depending on hot gas temperature). The bed pressure then falls to about 21 $\mathrm{kPa}$ (process 2-3) as a result of opening the valve connecting the evaporator to bed. Methanol vapour condenses at constant pressure corresponding to ambient temperature; the condensation process ends at point 4. As bed, (2) is cooled by ambient air the evaporator pressure falls to $5 \mathrm{kPa}$ with corresponding saturation temperature of $3^{\circ} \mathrm{C}$. The evaporation process starts at point 5 and ends at point 1 .

\section{Conclusion}

- Exhaust gas temperature strongly affected the adsorption process. It was found that the minimum exhaust gas temperature to release methanol vapour from activated carbon was $60^{\circ} \mathrm{C}$

- The chilled water temperature depends on the exhaust gas temperature, evaporator pressure, adsorption time and whole cycle time. The minimum chilled water temperature that is produced in this work was $7^{\circ} \mathrm{C}$, when the adsorption time was $90 \mathrm{~min}$ and the evaporation time was $30 \mathrm{~min}$

- Cycle COP is affected strongly by exhaust gas temperature. It was found that the maximum cycle COP was 0.31 when the exhaust gas temperature was $120^{\circ} \mathrm{C}$ and the generator temperature was $80^{\circ} \mathrm{C}$. It is known that the methanol decomposes at temperature around 110 to $120^{\circ} \mathrm{C}$, thus, the decrease in COP is reasonable for higher generator temperature

\section{Acknowledgement}

The authors acknowledge Mr. Thabt Jamel, chief engineer/in the engineering technical college/Baghdad, Middle Technical University, for his technical support given in completing this work. Special thanks to Dr. 
Florian Ion Tiberiu Petrescu, Associate Editor and the reviewers for their commitment in reviewing the paper.

\section{Author's Contributions}

Abdul Hadi N. Khalifa: Created the main idea of the work, design of the system, analyzing the results and writing manuscript.

Ali H. Jabbar: Build the adsorption unit, taking readings and draw the result in the forms of graphs.

Jamal A. Muhsin: Gave some advice and tips.

\section{Ethics}

The manuscript has not been published or accepted for publication elsewhere, either in whole or in part, whether in English or another language. The manuscript meet ethical standards applicable to the research discipline and does not violate any intellectual property right of any person.

\section{References}

Jiangzhou, S., R.Z. Wang, Y.Z. Lu, Y.X. Xu and J.Y. $\mathrm{Wu}, 2002$. Experimental investigations on adsorption air-conditioner used in internalcombustion locomotive driver-cabin. Applied Thermal Eng., 22: 1153-1162. DOI: $10.1016 / \mathrm{S} 1359-4311(02) 00036-4$

Karnaukhov, A.V., 2001. Role of the biosphere in the formation of the Earth's Climate: The Greenhouse Catastrophe. Biophysics, 46: 1078-1088.

Khalifa, A.H.N., F.M. Hussein and F.M. Hadi, 2011. Experimental study on two beds adsorption chiller with regeneration. Modern Applied Sci., 5: 43-52. DOI: $10.5539 /$ mas.v5n4p43
Obert, E.F., 1973. Internal Combustion Engines and Air Pollution. 1st Edn., Intext Educational Publ., New York, pp: 740.

Sharafian, A. and M. Bahrami, 2014. Assessment of adsorber bed designs in waste-heat driven adsorption cooling systems for vehicle air conditioning and refrigeration. Renewable Sustainable Energy Rev., 30: 440-451. DOI: 10.1016/j.rser.2013.10.031

Tiwari, H. and G.V. Parishwad, 2012. Adsorption refrigeration system for cabin cooling of trucks. Int. J. Emerg. Technol. Adv. Eng., 2: 337-342.

Wang, R., Z. Lu, L. Wang and Z. Xia, 2006. A High Efficient Adsorption Icemaker for Fishing Boat. Proceedings of the International Refrigeration and Air Conditioning Conference, Jul. 17-20, School of Mechanical Engineering, pp: 1-9.

Zhang, L.Z., 2000. Design and testing of an automobile waste heat adsorption cooling system. Applied Thermal Eng., 20: 103-114. DOI: 10.1016/S1359-4311(99)00009-5

Zhang, L.Z. and L. Wang, 1997. Performance estimation of an adsorption cooling system for automobile waste heat recovery. Applied Thermal Eng., 17: 1127-1139. DOI: 10.1016/S1359-4311(97)00039-2

Zhong, Y., K.L. Wert and T. Fang, 2010. An adsorption air-conditioning system to reduce engine emissions and fuel consumption for heavy-duty vehicles. Proceedings of the International Refrigeration and Air Conditioning Conference at Purdue, Jul. 12-15, School of Mechanical Engineering. 